\title{
Significance of eLearning at Sunway University: A perspective from Art and Design students
}

\author{
Saravanamalar A/P Surarajah \\ Faculty of Arts, Sunway University, Malaysia \\ saravanas@sunway.edu.my
}

\begin{abstract}
Online learning platforms give a great opportunity for various types of learners with different learning abilities to learn at their own pace anytime, anywhere and at any cost. Some of the most common online platforms are Moodle, Blackboard and Virtual Learning Environment (VLE). Each platform has its own impact to the learners. It can be a positive or negative impact depending on the content of the subject matter, layout, design and user friendliness of the course site. However, online platforms can be significant for many learners but not for all. This paper studies the significance of using Blackboard (known as eLearn at Sunway University) in teaching and learning at Department of Art and Design, Sunway University. 79 students at this department had participated in the survey and given their feedback on using eLearn and about $74.7 \%$ of them are local students and the rest are international students. Teaching mathematics online can be different from history; teaching spiritual values can be different from science. However, all online teachings and learnings have something in common. There are some factors that make the online facilitators rise and fall at times. This paper also discovers learners' expectation for a better eLearn experience.
\end{abstract}

Keywords: eLearn, perspective, teaching, learning, impact

"We need to bring learning to people instead of people to learning." Elliot Masie, Masie Center (@emasie) (Gutierrez)

\section{Introduction}

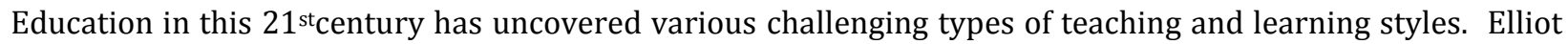
Masie, who leads the MASIE centre in New York and an analyst who has used the phrase e-Learning for the first time, said that learning should be brought to the learners (2015 MASIE Events). One of the effective ways to bring knowledge to learners' doors is through eLearn. Sunway University that is located in the Klang Valley has a very empowering vision, which is 'To be a World Class University' (Sunway.edu.my). Besides providing latest infrastructure and conducive study environment, it urges all the academicians to utilise eLearn in their classes. ELearn uses Blackboard platform to teach and learn online. Thus, this study focuses on identifying the significance of using eLearn among students in the Department of Art and Design to facilitate online teaching and learning. The aim of this study is to reveal a general perspective of students at Department of Art and Design about using eLearn in the university. The main objectives are:

a) To encourage students and academicians to use eLearn in teaching and learning.

b) To revise the use of eLearn based on students' feedback.

c) To assess the success of eLearn in teaching and learning at Department of Art and Design.

This study is conducted among 79 students who have enrolled in three various programmes offered in the department. The programmes are namely, Diploma in Graphic and Multimedia Design, Diploma in Interior Design and Diploma in Fine Art. The students who have participated in the study are from Malaysia, Indonesia, Vietnam, Korea, Sri Lanka, Yemen, Tanzania and others countries and it includes students from semester one to eight. It does not include students from other departments and Faculties at Sunway University. As to study the significance of eLearn at Sunway University, students at Department of Art and Design have been selected for this pilot study. ELearn platform at Sunway University is accessible for registered students and full time staff at anytime and anywhere on any networked devices. Students and staff also may download the eLearn app for their tablets and mobile devices. It enables smarter accessing for better online teaching and learning. The main interface of eLearn log in is shown in Figure 1. 


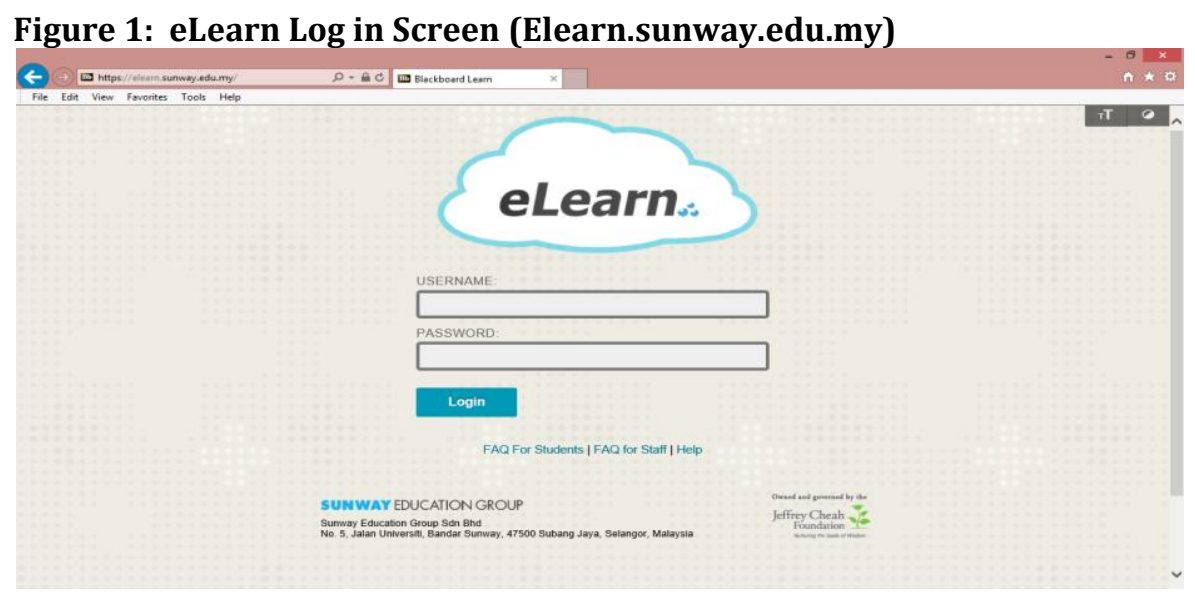

\section{Literature Review}

Prior to this study, there were several literatures that had been reviewed and inspired to conduct this study at Department of Art and Design at Sunway University. All the selected literature are very recent and within five years of study. Review of a literature gives an overview of research strategy to the study that will be conducted and provides strong grounds to the study as well. The first review done is on The Effectiveness of e-Learning Portal in Distance Education as Perceived by Students in Universiti Sains Malaysia by Siti Sarah Mohd Johari and Issham Ismail from University Sains Malaysia (USM). This study conducted to find out the effectiveness of e-learning portal used in distance education at USM for academic session in years 2007/2008. There were 1084 respondents who had given their feedback in this study. This research revealed that academically the e-learning portal is effective and facilitates the distance learning. Besides assisting online teaching and learning, the e-learning portal also is created as a hub for retrieving academic resources such as articles, books, computer software, comments from subject matter experts, and consultation from academicians. As time goes by, the portal had become an essential tool for both students and academicians in distance learning (Mohd Johari \& Ismail, 2011).

The second review is a study conducted in India by Mehra and Omidian in 2011. They believe that elearning could provide a better teaching and learning environment in classroom. This case study is conducted in Panjab University among 400 post graduate students examining their attitudes towards elearning. About three quarter of the respondents provided positive feedback towards elearning. Moreover many students also were found interested to adopt elearning as their choice of better learning platform (Mehra \& Omidian, 2015). Another literature review on elearning was conducted in Gulf Region in 2011 by Tubaishat \& Lansari. This literature review examined the readiness and perception of students adopting elearning in their university. The study was conducted in College of Information Technology, Zayed University, United Arab Emirates. It is a well-known and competitive university compared to other leading international universities. About 78\% of students said that elearning has positive impact in the teaching and learning process and $75 \%$ of students had agreed that they can learn effectively via elearning. This study clearly proves that elearning is one of the most preferred mode of teaching and learning methods in the university. Besides these, the study also had proved that students are more self-controlled on their self-paced learning (Tubaishat \& Lansari, 2011).

The next review is from Saudi Arabia, another Middle East country. According to this article, one of the studies was carried out by Harvey in 2003 at King Fahd University of Petroleum \& Minerals (KFUPM), Dhahran in Saudi Arabia. The study was to investigate students' behaviour on using computers and the impact of elearning in their general academic achievement. About 172 male students participated in the study. The results showed that majority of the students were positive using computer based learning and there was an increase in students' performance at the semester end (Jabli \& Qahmash, 2013). One of the proposed strategic model for implementing elearning is recommended by Madar and Willis. They have identified the lack of a strategic model to implement eLearning in higher institutions. Thus they have proposed the Funnel Model as shown Figure 2. 
Figure 2: The proposed Funnel Model for eLearning (Madar \& Willis, 2014)

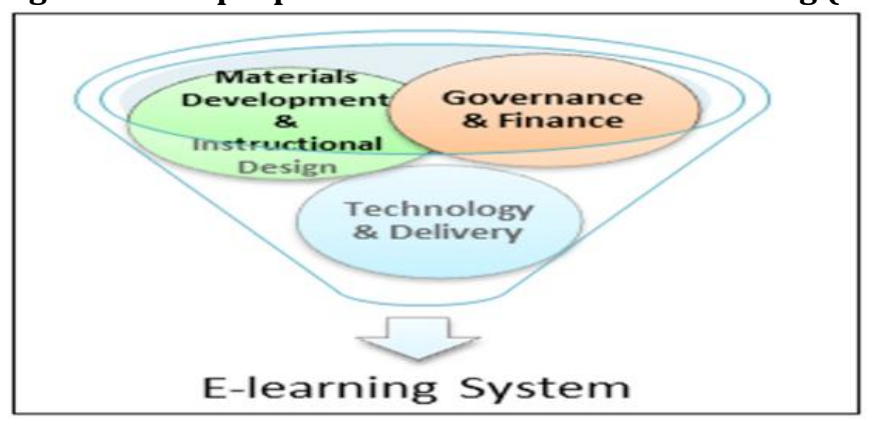

They have suggested that content development and instructional design, technology and delivery and governance and finance have to be integrated to achieve a better elearning model. The three elements are in fact depicting pedagogy, technology and governance elements that have to be well coordinated for a successful implementation of elearning experience (Madar \& Willis, 2014). The final literature review that had been studied is about E-Learning and Its Effects on Teaching and Learning in a Global Age by Jethro, Grace and Thomas from Nigeria. This study identified a number of advantages of using elearning for better learning experience. It discovered that elearning improved the teaching and learning process, provided better self-paced learning environment and promoted creative and active learning platform (Jethro, Grace \& Thomas, 2012).

\section{Methodology}

This quantitative study is designed for students at Department of Art and Design, Faculty of Arts, Sunway University, located in Selangor, Malaysia. A questionnaire was designed for students to give their feedback on the significance of using eLearn at Sunway University. There were 100 students who have participated in the survey and only 79 were collected successfully. All the students were from three different programmes, which are Diploma in Graphic and Multimedia Design, Diploma in Interior Design and Diploma in Fine Art. A questionnaire with 30 questions was distributed randomly among students from semester one to eight. Questionnaire was designed using simple English with straight forward and focused questions. The questionnaire also had been divided into three main parts: Demographic Study, Research Study and General Study. Demographic and Research studies included close-ended questions with five-point Likert Scale questions at the end of Research Study. While General Study had open-ended questions for students to give their feedback and opinions about eLearn. This study was conducted at the end of 2014 before the semester break started at the university. In the beginning it was quite difficult to get feedback from students since most of them were preparing for final examinations and project presentations. However, most of them were quite cooperative and completed the questionnaire within the time frame given. Data collected were analysed using SPSS software and MS Excel to display the results effectively.

\section{Results and Discussions}

Demographic Study: This section has five main questions, studying the gender, nationality, programmes and semester details. The first question is about gender study. From the total of 79 students, $46 \%$ (36 students) of participants are male students and 54\%(43 students) of them are female. (Please refer to Figure 3). According to Executive Summary from University of Arizona, female respondents are usually more prominent in giving feedback in a survey compared to male respondents. (University of Arizona, 2014). From the following questions, among the male students, $72 \%$ of them are Malaysians and $28 \%$ are international students from Tanzania, Vietnam, Sri Lanka and other countries where the participants did not indicate their nationalities. 61.1\% of male students have enrolled in Diploma in Graphic and Multimedia Design and 38.9\% of the rest have enrolled in Diploma in Interior Design. No male students from Diploma in Fine Art have participated in this study. Among all the male students, $6 \%$ are from semester one, $19 \%$ are from semester two, $6 \%$ are from semester three, $14 \%$ are from semester four, $19 \%$ are from semester five, $11 \%$ are from semester six, $22 \%$ are from semester seven and $3 \%$ are from semester eight. While among the female 
students, $77 \%$ of them are Malaysians and 23\% are international students from Korea, Indonesia and Yemen. $55.8 \%$ of female students have enrolled in Diploma in Graphic and Multimedia Design and 32.6\% of the students have enrolled in Diploma in Interior Design and 2.3\% have registered for Diploma in Fine Art. Among all the female students, $23 \%$ are from semester one, $21 \%$ are from semester two, $7 \%$ are from semester three, $19 \%$ are from semester four, $5 \%$ are from semester five, $7 \%$ are from semester six, $19 \%$ are from semester seven and none are from semester eight.

Figure 3: Gender Analysis: Students who have participated in the study

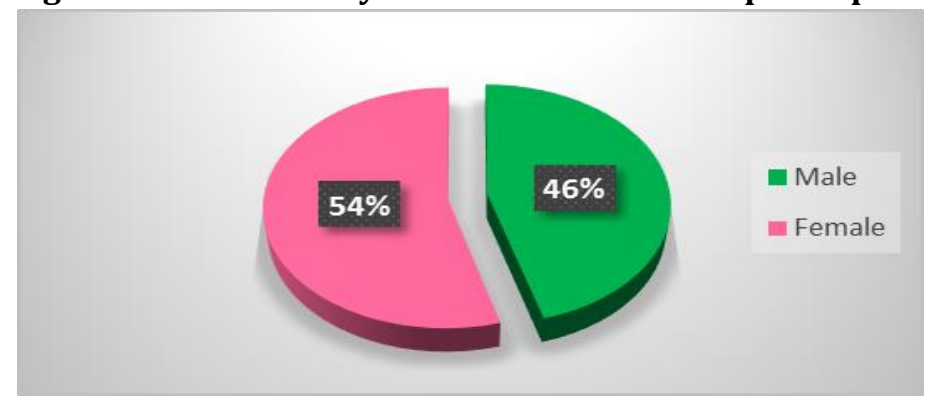

Research Study: In this section, the first five questions are about eLearn and subjects at eLearn. Question 7 finds out the number of subjects that students have enrolled in eLearn. Among the male students, $28 \%$ of them have not registered in eLearn at all. 19\% of them have enrolled in one or two subjects in eLearn. $8 \%$ of the male students have registered in three subjects in eLearn and $22 \%$ of them have enrolled in five subjects. However, $3 \%$ of the students did not answer this question. Among the female students, $28 \%$ of them did not enrol in eLearn. $30 \%$ of them have registered for one subject, $16 \%$ of them have registered for two subjects, $2 \%$ have enrolled in four subjects, $16 \%$ have enrolled in five subjects and $7 \%$ of the female students did not answer this question. Question 8, reveals that $83 \%$ of the male students have used eLearn and $17 \%$ of them did not use eLearn at all. Meanwhile $77 \%$ of the female students have used eLearn and $23 \%$ of the rest have not used eLearn. Question 9 is about the frequency of visiting eLearn course sites by the students. Combining both groups, it had been found out that $57.1 \%$ of the students visit at least once a week, $23.8 \%$ of them visit twice a week, $7.9 \%$ visit three times a week, 1.6 of them visit four or five times a week, $3.2 \%$ of them visit once a semester or less than a week, and $1.6 \%$ of them did not answer this question. Question 10 reveals the academic resources that are accessed by students at eLearn. As shown in Figure 4, 78\% of the students are accessing lecture notes, followed by $46 \%$ of them downloading assignment brief and $41 \%$ getting the lab notes from eLearn. This study also shows that only $5 \%$ are actively participate in the forum. Academicians need to focus on this issue and improve the two-way communications at online Forum at eLearn.

Figure 4: Materials accessed by all students at eLearn

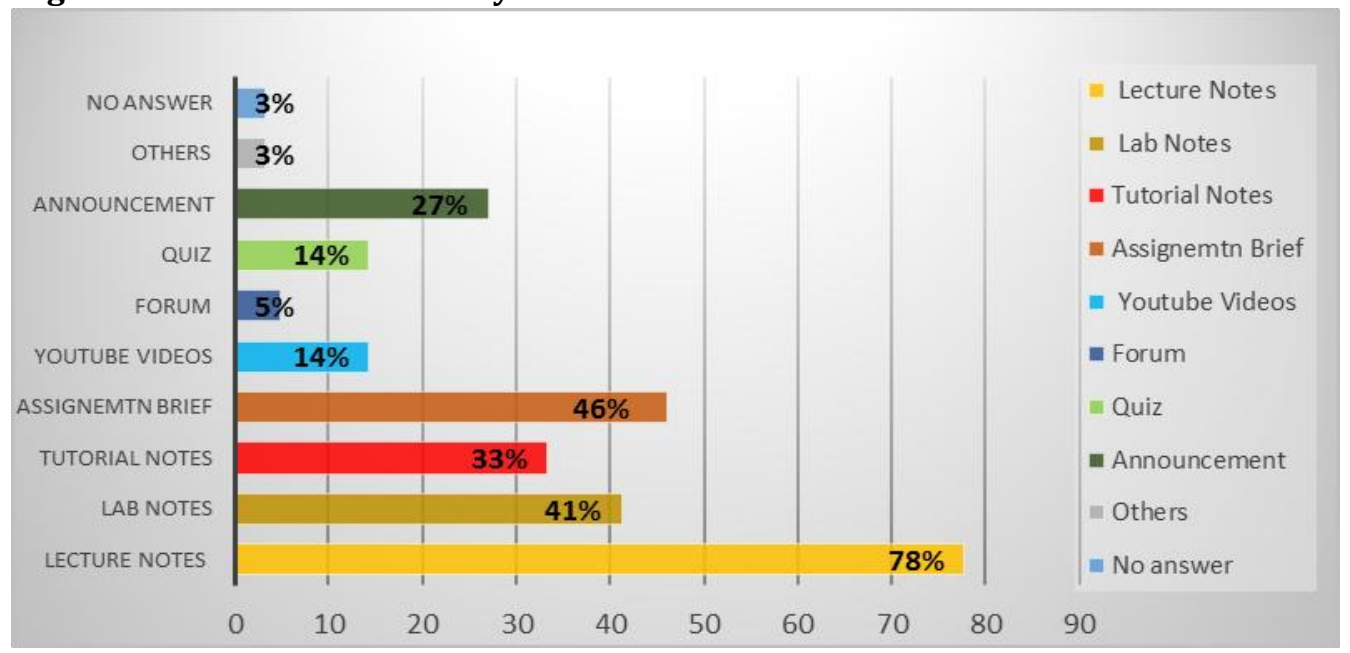


Questions 11 to 25 use the five-point Likert Scale to study the feedback from the eLearn users. Students who have opt for not using eLearn, would skip this section and fill the final open-ended question section, which is known as General Study. The summary of the results are shown in Table 1 below:

Table 1: Feedback from students who have used eLearn (in \%)

\begin{tabular}{|c|c|c|c|c|c|c|c|c|c|c|}
\hline Likert Scale & 5 & 4 & 3 & 2 & 1 & No answer & $\begin{array}{l}\text { Number } \\
\mathbf{N}\end{array}$ & $\begin{array}{l}\text { Mean } \\
\text { M }\end{array}$ & $\begin{array}{l}\text { Variance } \\
\mathrm{V}\end{array}$ & $\begin{array}{l}\text { Standard Deviation } \\
\mathrm{S}\end{array}$ \\
\hline 11. ELearn is good & 11.1 & 54.0 & 22.2 & 1.6 & 3.2 & 7.9 & 6 & 16.7 & 388.1 & 19.7 \\
\hline 12. Access Weekly & 22.2 & 49.2 & 15.9 & 4.8 & 3.2 & 4.8 & 6 & 16.8 & 388.2 & 19.7 \\
\hline 13. Other academic materials & 17.5 & 46.0 & 23.8 & 7.9 & 1.6 & 3.2 & 6 & 16.7 & 279.4 & 16.7 \\
\hline 14. Attractive interface & 12.7 & 33.3 & 30.2 & 14.3 & 6.3 & 3.2 & 6 & 16.7 & 154 & 12.4 \\
\hline 15. Prompts one way communication & 4.8 & 42.9 & 39.7 & 4.8 & 4.8 & 3.2 & 6 & 16.7 & 364.5 & 19.1 \\
\hline 16. Feedback within two days & 15.9 & 33.3 & 33.3 & 9.5 & 4.8 & 3.2 & 6 & 16.7 & 185.5 & 13.6 \\
\hline 17. Posted comments at discussion forum & 14.3 & 30.2 & 23.8 & 9.5 & 17.5 & 3.2 & 6 & 16.4 & 94.5 & 9.7 \\
\hline 18. Downloading notes & 15.9 & 52.4 & 14.3 & 9.5 & 4.8 & 3.2 & 6 & 16.7 & 331.3 & 18.2 \\
\hline 19. Accessed YouTube or quiz & 14.3 & 34.9 & 23.8 & 9.5 & 14.3 & 3.2 & 6 & 16.7 & 125.5 & 11.2 \\
\hline 20. Lecturer is active & 27.0 & 39.7 & 19.0 & 6.3 & 4.8 & 3.2 & 6 & 16.7 & 214.5 & 14.6 \\
\hline 21. Clear instruction to enrol & 28.6 & 41.3 & 22.2 & 3.2 & 1.6 & 3.2 & 6 & 16.7 & 274 & 16.6 \\
\hline 22. Encourage me to access eLearn weekly. & 25.4 & 36.5 & 25.4 & 4.8 & 4.8 & 3.2 & 6 & 16.7 & 201.8 & 14.2 \\
\hline 23. ELearn always accessible anywhere anytime & 27.0 & 46.0 & 19.0 & 4.8 & 0.0 & 3.2 & 6 & 16.7 & 314.5 & 17.7 \\
\hline 24. Classroom must equip with pc to access eLearn & 19.0 & 47.6 & 23.8 & 3.2 & 3.2 & 1.6 & 6 & 16.4 & 320.5 & 17.9 \\
\hline 25. ELearn fulfils my learning experience at DAD & 19.0 & 41.3 & 30.2 & 1.6 & 4.8 & 1.6 & 6 & 16.4 & 278 & 16.7 \\
\hline
\end{tabular}

The study shows that question 11, I find that eLearn is a good online Learning environment, has the mean value of 16.7 with highest standard deviation, $S=19.7$. Question 2, I can access to weekly class notes at eLearn has the highest mean value of 16.8 with highest $S=19.7$ as well. This is a good remark that students are having a positive perception about eLearn at Sunway University and expecting weekly notes and want the lecturers to be actively participate in eLearn. Questions $13,14,15,16,18,19,20,21,22$ and 23 have the same mean value of 16.7. Questions 17, 24 and 25 have the lowest mean value of 16.4. Meanwhile the questions 13 and 25 have the same standard deviation value of 16.7. Questions 15 and 18 have a little higher standard deviation value of 19.1 and 18.2 respectively. Questions 21,23 , and 24 have the standard deviation values of 16.6, 17.7 and 17.9. Other questions have standard deviation values below 15 and these criteria have to be taken note for improvement by the academicians in general. The lowest standard deviation value is question 17 which has only 9.7. This shows that forum has not been active as expected by students. Academicians need to create a positive two way communication in the forum for students to actively engage in eLearn.

General Study: This is the final section of the questionnaire that has 5 open-ended questions. These questions were intended to get feedback from students for betterment of eLearn course sites. Question 26 seeks students' perception on eLearn compared to other Social Network sites such as Facebook. Question 27 identifies if students like to use eLearn. Questions 28 and 29 unveil the pros and cons of using eLearn and the final question discovers the recommendations from students for a better eLearn environment. For Question 26, majority of students had agreed that Facebook is better than eLearn. This is because Facebook has simpler interface design and is user friendly compared to eLearn. Facebook also has lots of other interesting topics whereas eLearn is very academic. Most of the students who have answered Question 27, disliked eLearn. They mainly use it for downloading notes and the interface is boring. Students who have answered question 28, highlighted the benefits if using eLearn is downloading lecture notes, lab notes and tutorial notes only. They did not find it interesting or conducive for online learning. In question 29, many students found in complicated and confusing interface design. Students also highlighted that it has many steps in eLearn to access information. Finally, in question 30, many students suggested that eLearn should have attractive layout, better navigation system, frequently update contents, and get connected to online social media.

\section{Conclusion}


This study is conducted to identify the significance of using eLearn among students at Department of Art and Design, Sunway University. Sunway University always strives its best to provide the best conducive environment for teaching and learning. As one of the attempts to fulfil students' self-paced learning, it introduced online platform called eLearn for students to enjoy better pedagogical environment. This study it has been discovered that many students do not find eLearn as interesting as other social network sites, especially Facebook. Most of the students are using eLearn for downloading and accessing lecture, lab and tutorial notes only. Academicians need to play a vital role improve the two-way communications via eLearn. As said by Steve Jobs, "Design is not just what it looks like or feels like, but how it works."(Eskills.ch, 2015). Although there are apps for downloading eLearn for mobile devices, the usage is not as expected by students. Thus, referring back to the objectives, academicians need to formulate better strategies to develop effective eLearn course sites for effective teaching and learning, revise the contents based on students' feedback and assess the results to create successful course sites.

Recommendations: Based on feedback obtained from students, a thorough analysis has to be done at department level to improve the quality of eLearn platform. Besides that more feedback should be obtained from students at various departments and faculties at Sunway University to get a better impression of the overall issue. Also it is important to get responses from academicians as well to understand their opinions on using eLearn and study the impact from the instructors' point of view. It is also recommended that academicians may need to be sent for eLearn trainings to improve themselves as online instructors. It is also suggested to conduct trainings or simplified demonstration sessions for students on how to navigate around eLearn environment. More studies on eLearn should be conducted at university level to provide an enhanced online teaching and learning environment.

\section{References}

2015 MASIE Events. (2015). Who is Elliott Masie. Masie.com. Retrieved 22 April 2015, from http://masie.com/MASIE-Information/who-is-elliott-masie.html

Elearn.sunway.edu.my. (2015). Blackboard Learn. Retrieved 22 April 2015, from https://elearn.sunway.edu.my/

Eskills.ch. (2015). eSkills | Training | Instructional Design | eLearning | Geneva. Retrieved 23 April 2015, from http://eskills.ch/workshops/

Gutierrez, K. (2015). 16 eLearning Quotes to Inspire You [SlideShare]. Info.shiftelearning.com. Retrieved 22 April 2015, from http://info.shiftelearning.com/blog/bid/295365/16-eLearning-Quotes-to-InspireYou-SlideShare

Jabli, N. \& Qahmash, A. (2013). The Benefits and Barriers of E-learning in Higher Education in Saudi Arabia. Journal Of Emerging Trends In Computing And Information Sciences, 4(11).

Jethro, O., Grace, A. \& Thomas, A. (2012). E-Learning and Its Effects on Teaching and Learning in a Global Age. International Journal of Academic Research In Business And Social Sciences, 2(1).

Madar, M. \& Willis, D. (2014). Strategic Model of Implementing E-Learning. International Journal of Scientific \& Technology Research, 3(5).

Mehra, V. \& Omidian, F. (2015). Examining Students' Attitudes Towards E-learning: A Case from India. Malaysian Journal of Educational Technology, 11(2).

Mohd Johari, S. \& Ismail, I. (2011). The Effectiveness of e-Learning Portal in Distance Education as Perceived by Students in Universiti Sains Malaysia. Malaysian Journal of Distance Education, 13(1), 47-57.

Sunway.edu.my. (2015). Vision \& Mission | Sunway University. Retrieved 22 April 2015, from http://sunway.edu.my/university/vision-mission

Tubaishat, A. \& Lansari, A. (2011). Are Students Ready to Adopt E-Learning? A Preliminary E-readiness Study of a University in the Gulf Region. International Journal of Information And Communication Technology Research, 1(5).

University of Arizona (2014). Student Sustainability Survey. Retrieved 23 April 2015, from http://studentaffairs.arizona.edu/assessment/documents/StudentSustainabilitySurveyReport_Final. pdf. 